\author{
Adama SAMAKE ${ }^{1}$ \\ Andrzej KOS ${ }^{2}$
}

\title{
COMPARISON OF DIFFERENT COOLING SYSTEMS USING COMPACT MODEL
}

\begin{abstract}
Due to the strong influence of temperature rising on integrated circuits performance and reliability, an adequate thermal analysis of their cooling systems is required during chip packaging in order to prevent the thermal catastrophe. In this paper, we propose an approach based on RC compact model, which enables in one hand an approximation of dynamic thermal behaviour and in other hand the accurate temperature computation at any measurement point of parallel plate fin heat sink with U-shape channels. Farther more, we present the impacts of convection coefficient on heat sink surface temperature using a simplified approach, which enables the temperature computation by using the RC thermal compact model. Due to the convection coefficient change of surrounding environment, the surfaces and mass of parallel plate fin heat sink with U-shape channels were reduced while enhancing heat transfer capability.
\end{abstract}

Keywords: Thermal compact models, integrated circuit, heat sink, temperature, active cooling

\section{Introduction}

The heat transfer from nowadays' integrated circuits interior to surrounding cooling air remains as a great challenge. Due to the exponential increasing of power density and high power dissipation at high frequency, decreasing the thermal stress has become one of the major issues for integrated circuits designers. Fig. 1 describes the experimental results of a research that was performed by Maudgali to determine the causes of microelectronic circuit failures [4]. As depicted in Fig.1, more than the half of the failures are the issues caused by temperature rising.

\footnotetext{
${ }^{1}$ Adama Samake, AGH University of Science and Technology, Faculty of Computer Science, Electronics and Telecommunications, Al. Mickiewicza 30, Krakow, Poland, PhD Student from Mali, e-mail: samake@student.agh.edu.pl

${ }^{2}$ Corresponding author: Andrzej Kos, AGH University of Science and Technology, Faculty of Computer Science, Electronics and Telecommunications, Al. Mickiewicza 30, Krakow, Poland, e-mail: kos@agh.edu.pl
} 
Due to the strong influence of operating temperature on the integrated circuits performance and reliability therefore, building an appropriate thermal compact model is needed in the stages of thermal analysis and temperature computation process of package. The thermal compact models may provide a good indicator of the chip thermal capability of a given package.

In order to enhance the thermal management of integrated circuit, one of the common means is the utilization of heat sink [1]. Their use allows the reduction of thermal resistance between circuit and cooling air by extending the exchange surface for heat transfer. They are recognized as effective tools that improve the heat transfer from integrated circuits to the surrounding cooling air. Hence, thermal modelling from integrated circuit to heat sink level is a crucial stage of system's construction. In [11] Andreas Tockhorn, Claas Cornelius, Hagen Saemrow and Dirk Timmermann proposed a method for the fine-grained modelling of temperature distribution in many-core systems based on Networks-on-Chip, which allows designers to model temperature distribution easily. Paper [8] proposed a technique based on co-simulation of packages given with RC compact model and the board, which provides further details of the heat transfer in board and accurate computation of junction temperature in packages. In [9] an algorithm has been presented in order to facilitate the time constant spectrum calculation in thermal simulator programs. The time constant spectrum is defined as the graphical representation of the whole time-constant and $\mathrm{R}$ magnitude in the step-function of lumped circuit. It may be used to present dynamic thermal behaviour of packages, assemblies and microsystems. In order to reduce integrated circuits' temperature by using Peltier heat pump and cooling fin, in [2] authors proposed an analytical method, which uses the dissipated power in the circuit as the control parameter to optimize the Peltier current. In [5] the author proposed a new rule for choosing the accurate number of Fourier series terms and for estimation the error in order to compute accurately the temperature over hybrid microelectronic.

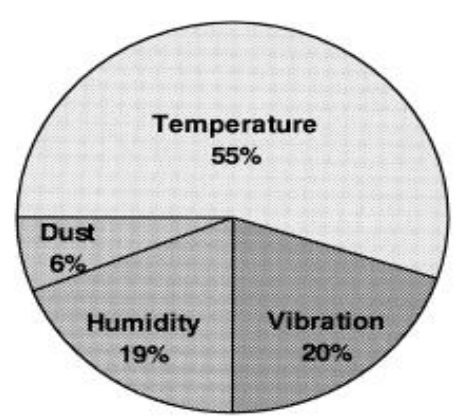

Fig.1 Origins of microcircuit failures [3] 


\section{Methodology}

\subsection{Analogy of electrical and thermal parameters}

Several techniques have been applied in order to study the dynamic thermal behaviour of microelectronic circuit/system attached to heat sink. Most of those methods are based on RC (resistance and capacitance) thermal compact models. The method of temperature computation described in this paper is based on the analogy between energy flow and the behaviour of RC electrical network [11]. The analogy between electrical and thermal parameters is described in [4].

Charging and discharging the capacitances in RC electrical network one may describe the transient thermal behaviour of a system (package). Fig. 2 depicts RC circuit for transient temperature and its response to voltage pulse. Equations (1) and (2) describe the response voltage amplitude $\mathrm{A}(\mathrm{t})$ of the circuit (from 0 to $\mathrm{U}_{\text {in }}$ and from $\mathrm{U}_{\text {in }}$ to 0 , respectively) [6].

$$
\begin{aligned}
& \mathrm{A}(\mathrm{t})=\mathrm{A}_{0}\left(1-\mathrm{e}^{-\mathrm{t} / \tau}\right) \\
& \mathrm{A}(\mathrm{t})=\mathrm{A}_{0} \mathrm{e}^{-\mathrm{t} / \tau}
\end{aligned}
$$

where: $\mathrm{t}$ is time in second (s)

$\tau$ is the time constant in second (s)

$\mathrm{A}_{0}$ is the output amplitude in volts (v).

It is assumed that the output amplitude reaches its steady state in time $3 \tau$.

$$
\tau=\mathrm{R} \mathrm{C}
$$

where: $\mathrm{R}$ is the resistance in ohms $(\Omega)$

$\mathrm{C}$ is the capacitance in farads $(\mathrm{F})$

Rising signal

at $\mathrm{t}=0, \quad \mathrm{~A}(\mathrm{t})=0$,

at $\mathrm{t}=>\infty, \quad \mathrm{A}(\mathrm{t})=>\mathrm{A}_{0}$,

at $\mathrm{t}=\tau, \quad \mathrm{A}(\mathrm{t})=0.63 \mathrm{~A}_{0}$

\section{Falling signal}

at $\mathrm{t}=0, \quad \mathrm{~A}(\mathrm{t})=\mathrm{A}_{0}$,

at $\mathrm{t}=>\infty, \quad \mathrm{A}(\mathrm{t})=>0$,

at $\mathrm{t}=\tau$,

$\mathrm{A}(\mathrm{t})=0.37 \mathrm{~A}_{0}$

From above condition, we can estimate thermal time constant for heating of the system as well as for its cooling stage.

The analogies between thermal and electrical parameters enable the modelling of the temperature distribution of the system by using RC electrical circuit. When a component inside integrated circuit is activated, it dissipates a certain amount of heat and becomes a heat source. The investigation described in this 
paper is based on a square integrated circuit (heat source) of small lateral dimensions situated at the centre of parallel plate fine heat sink with U-shape channels.
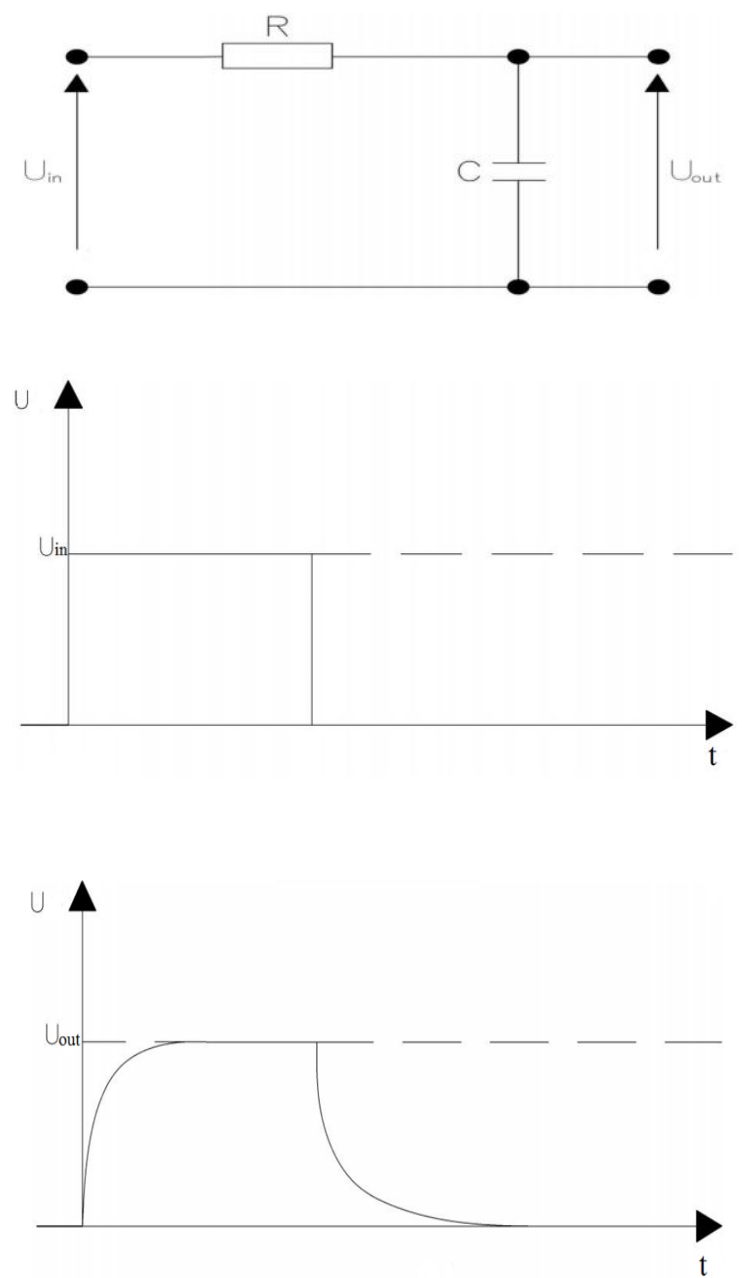

Fig. 2. RC analogue for the temperature transient of integrated circuit and its response to a voltage pulse [6]

The heat sink is made of aluminium, Fig. 3 depicts (a) integrated circuits placed on plate fin heat sink geometrical centre, and (b) equivalent thermal network for the structure - RC network model. In order to access one dimension heat transfer we assume that the heat transfer occurs from base surface of integrated circuit to different heat fins of the heat sink. 


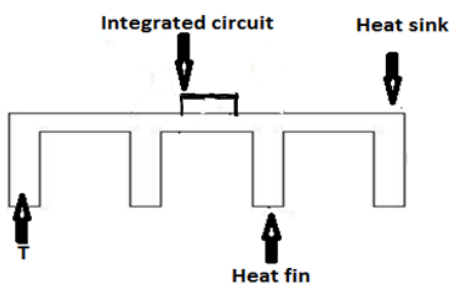

(a)

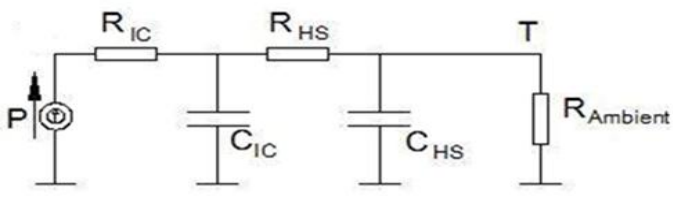

(b)

Fig.3 (a) Integrated circuits placed on plate fin heat sink geometrical centre, (b) Equivalent thermal network for the structure, RC network model, where: $\mathrm{P}$ is the power generated by the integrated circuit, $\mathrm{R}_{\mathrm{IC}}$ and $\mathrm{C}_{\mathrm{IC}}$ are respectively the thermal resistance and capacitance of integrated circuit, $\mathrm{R}_{\mathrm{HS}}$ and $\mathrm{C}_{\mathrm{HS}}$ are respectively the thermal resistance and capacitance of heat sink, $\mathrm{R}_{\text {Ambient }}$ is the thermal resistance between the heat sink and the ambient, $\mathrm{T}$ is heat fin's temperature

\subsubsection{Resistance}

The Thermal resistance depends on the distance, area of cross section and thermal conductivity of material.

$$
\mathrm{R}_{\mathrm{th}}=\frac{l}{\lambda S}
$$

where: $\mathrm{R}_{\mathrm{th}}$ is the thermal resistance in $\mathrm{KW}^{-1}$

$l$ is the distance between two points in $\mathrm{m}$

$\mathrm{S}$ is the area of cross section in $\mathrm{m}^{2}$

$\lambda$ is the thermal conductivity in $\mathrm{Wm}^{-1} \mathrm{~K}^{-1}$

As the parallel plate fin heat sink with U-shape channels has a certain number of fins therefore, equation (4) may be written as follow:

$$
\begin{aligned}
& \mathrm{R}_{\mathrm{th} 0}=\frac{\beta}{\lambda \Phi}+\frac{\varepsilon}{\lambda \psi} \\
& \mathrm{R}_{\mathrm{th} 1}=\frac{\beta}{\lambda(2 \Phi+\varepsilon)}+\frac{\varepsilon}{\lambda \psi} \\
& \cdot \\
& \cdot \\
& \mathrm{R}_{\mathrm{thn}}=\frac{\beta}{\lambda((\mathrm{n}+1) \Phi+(\mathrm{n} \varepsilon))}+\frac{\varepsilon}{\lambda \psi} \\
& \mathrm{n}=0,1,2,3, \ldots
\end{aligned}
$$

where: $R_{t h n}$ is the thermal resistance of a specific fin including surface from heat source in $\mathrm{KW}^{-1}$

$\mathrm{n}$ is the number of fins whereby $\mathrm{n}=0$ is the fin nearest to heat source.

$\beta$ is the heat sink base thickness in $\mathrm{m}$ 
$\Phi$ is the area of space between two fins in $\mathrm{m}^{2}$

$\varepsilon$ is the fin thickness in $\mathrm{m}$

$\psi$ is the fin area in $\mathrm{m}^{2}$

$$
\psi=\mathrm{gb}
$$

where: $\mathrm{g}$ is the heat sink base width in $\mathrm{m}$

$\mathrm{b}$ is the fin height in $\mathrm{m}$

$$
\Phi=\mathrm{gz}
$$

where: $\mathrm{z}$ is the fin spacing in $\mathrm{m}$

\subsubsection{Capacitance}

The thermal capacitance depends on the geometry and physical parameters of material.

$$
\mathrm{C}_{\mathrm{th}}=\mathrm{Mc}_{\mathrm{p}}
$$

where:

$\mathrm{C}_{\mathrm{th}}$ is the thermal capacitance in $\mathrm{J} \mathrm{K}^{-1}$

$\mathrm{M}$ is the mass in $\mathrm{kg}$

$c_{p}$ is the specific heat in $\mathrm{J} \mathrm{kg}^{-1} \mathrm{~K}^{-1}$

The mass is:

$$
\mathrm{M}=\rho \mathrm{V} \Leftrightarrow \mathrm{M}=\rho \mathrm{Se}
$$

where: $\rho$ is the density in $\mathrm{kgm}^{-3}$

$\mathrm{V}$ is the volume in $\mathrm{m}^{3}$

$\mathrm{e}$ is the thickness in $\mathrm{m}$

As the parallel plate fin heat sink with U-shape channels has a certain number of fins therefore, equation (8) may be rewritten as follow:

$$
\begin{aligned}
& \mathrm{C}_{\mathrm{th} 0}=\frac{1}{\rho \beta \operatorname{cp} \Phi}+\frac{1}{\rho \varepsilon c p \psi} \\
& \mathrm{C}_{\mathrm{th} 1}=\frac{1}{\rho \beta \operatorname{cp}(2 \Phi+\varepsilon)}+\frac{1}{\rho \varepsilon \mathrm{cp} \psi} \\
& \cdot \\
& \cdot \\
& \mathrm{C}_{\mathrm{thn}}=\frac{1}{\rho \beta \operatorname{cp}((\mathrm{n}+1) \Phi+(\mathrm{n} \varepsilon))}+\frac{1}{\rho \varepsilon \mathrm{cp} \psi} \\
& \mathrm{n}=0,1,2,3, \ldots
\end{aligned}
$$


where: $\mathrm{C}_{\mathrm{thn}}$ is the thermal capacitance of a specific fin including surface from heat source in $\mathrm{JK}^{-1}$

Hence, the resistance between the heat sink and ambient may be calculated by using the formula below [3].

$$
\mathrm{R}_{\mathrm{amb}}=\frac{1}{\mathrm{~h} \mathrm{~S}}
$$

where: $\mathrm{R}_{\mathrm{amb}}$ is the ambient resistance in $\mathrm{WK}^{-1}$

$\mathrm{h}$ is the convection coefficient in $\mathrm{Wm}^{-2} \mathrm{~K}^{-1}$

\subsection{Temperature computation idea}

The basic concept of this work is to divide the heat sink surface area into distributed parameters (Fig.3b) i.e. RC-elements. Therefore, the dynamic thermal behaviour of the heat sink surface may be approximated by charging and discharging the capacitances in RC circuit network in a given time constant. Hence, the two principal stages of temperature calculation are the following:

- First, the thermal parameters i.e. resistances, capacitances and ambient resistance values are calculated by using equation (5), (10) and (11) respectively. The number of heat fins should depend on the desire accuracy and should be equidistant from one to the other. It is assumed that the heat source is situated at the geometrical centre of heat sink base surface and the heat fin surface is isothermal. In order to calculate the ambient resistance, the one-side natural convection is assumed.

- Second, the temperature computation is performed by a circuit simulator (LTspiceIV), the resistances and capacitances value obtained in the first step are used in LTspiceIV RC circuit network. The current source (Power) is used as supply. The circuit is composed of certain amount of resistances and capacitances connected together. The capacitances are directly connected to ground and finally, the whole circuit is connected to the ambient resistance. As result, the voltage values of all nodes in LTspiceIV RC circuit are generated. They are interpreted as the temperature value of different heat fins.

\section{Temperature computation algorithm}

The calculation of thermal parameters method was based on equations (5), (10) and (11). Their values were used in RC circuit and the temperature compu- 
tation was performed by the LTspiceIV, which is a well-known program for electrical circuit simulation. Due to the analogies existing between electrical and thermal parameters, the program allows the thermal analysis of the system, Fig. 4.

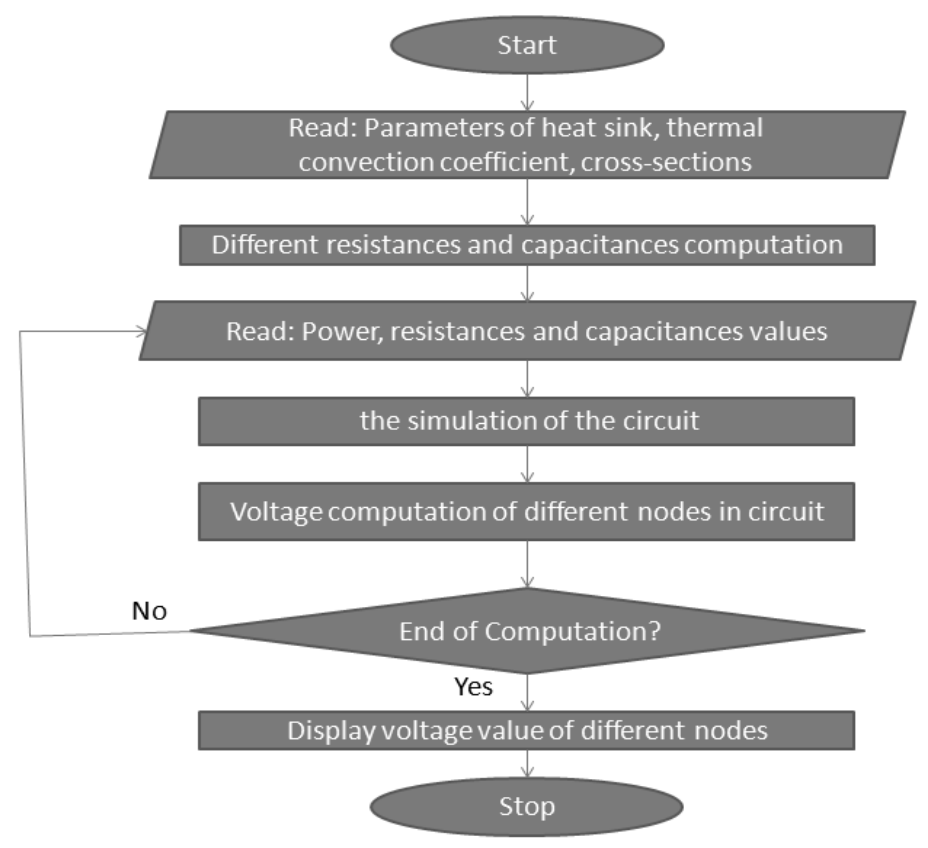

Fig.4. Algorithm of thermal analysis of the system (integrated circuit placed on a heat sink)

\section{Evaluation of efficiency of different cooling techniques}

In the following section, we perform the temperature computation of two different cooling systems by using our approach, Fig.5. Hence, the first case is composed of an integrated circuit situated at the geometrical centre of a large dimension heat sink made by aluminium that has sixteen heat fins. In the second case the integrated circuit is placed on the geometrical centre of an active fan heat sink, which is the half of the large dimension heat sink attached to a fan. For symmetrical reason Fig.5a and Fig.5b depict the half of heat sink utilized to first and second case respectively. In order to evaluate the effectiveness of both cooling methods, we compare the temperature results obtained from different cooling systems. Table 1 contains the parameters of different cooling systems and the ambient temperature was set to $298 \mathrm{~K}\left(25^{\circ} \mathrm{C}\right)$. 
(a)

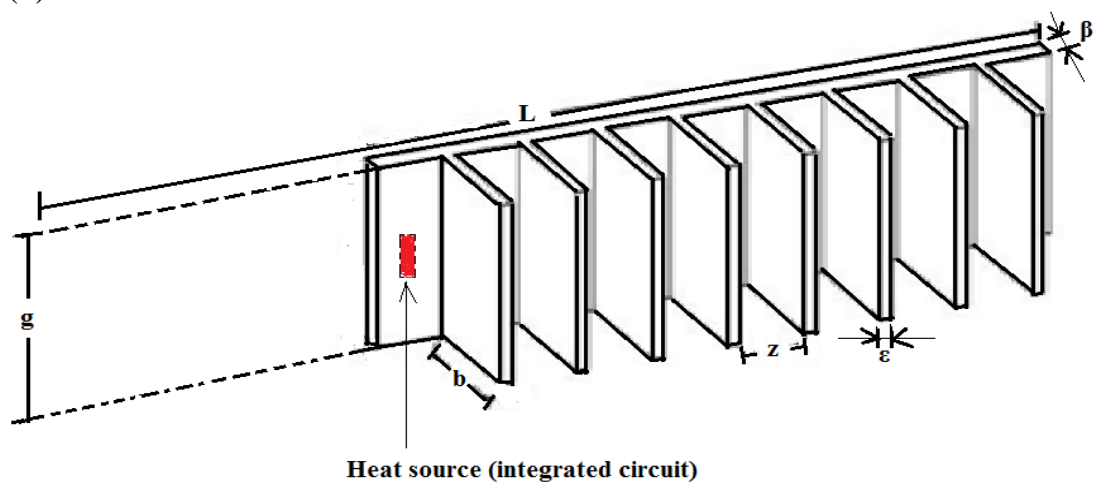

(b)

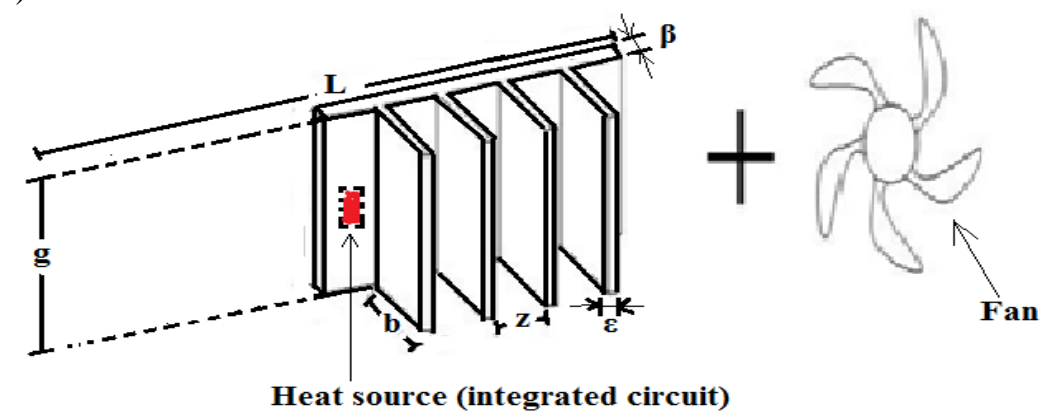

Fig.5 (a) large dimension heat sink and (b) active fan heat sink

Table1. Different Parameters of the systems

\begin{tabular}{|l|l|l|}
\hline Name of parameters & Symbol & Values \\
\hline Heat sink fin thickness & $\varepsilon$ & $5 \mathrm{~mm}$ \\
\hline Heat sink fin height & $\mathrm{b}$ & $150 \mathrm{~mm}$ \\
\hline Distance between fins & $\mathrm{z}$ & $40 \mathrm{~mm}$ \\
\hline Heat sink base width & $\mathrm{g}$ & $90 \mathrm{~mm}$ \\
\hline Heat sink base length & $\mathrm{L}$ & $360 \mathrm{~mm}$ \\
\hline Heat sink base thickness & $\beta$ & $10 \mathrm{~mm}$ \\
\hline Conductivity of heat sink & $\lambda$ & $204.2 \mathrm{~W} \times \mathrm{m}^{-1} \times \mathrm{K}^{-1}$ \\
\hline Convection coefficient & $\mathrm{h}$ & $\begin{array}{l}\text { Natural convection } \\
\mathrm{h}=20 \mathrm{~W} \times \mathrm{m}^{-2} \times \mathrm{K}^{-1} \\
\text { Forced convection } \\
\mathrm{h}=40,60,80 \text { and } 100 \mathrm{~W} \times \mathrm{m}^{-2} \times \mathrm{K}^{-1}\end{array}$ \\
\hline $\begin{array}{l}\text { Power dissipated by inte- } \\
\text { grated circuit }\end{array}$ & $\mathrm{P}$ & $10 \mathrm{~W}$ \\
\hline Density of heat sink & $\rho$ & $2707 \mathrm{~kg}^{-1} \times \mathrm{m}^{-3}$ \\
\hline Specific heat of heat sink & $\mathrm{c}_{\mathrm{p}}$ & $896 \mathrm{~J} \times \mathrm{kg}^{-1} \times \mathrm{K}^{-1}$ \\
\hline
\end{tabular}




\section{Results and discussion}

The proposed approach and compact model are used to compute the temperature variation over the surface of parallel plate fin heat sink with U-shape channels. As depicted in Fig. 6 even a small increase of convection coefficient leads to enhancement of cooling system thermal capability. Hence, the presence of active fan improves the heat transfer capability of the system. Both cooling systems used in our investigation have advantages and disadvantages depending on the application domain. Therefore, the large dimension heat sink is heavier, less efficient and bulky, however it doesn't require any extra energy consumption, which is contrary to the active fan heat sink. Thus the application of a fan required extra energy consumption and causes noise. The increase in convection coefficient leads to the small discrepancy between temperature values of different fins, owing to the high heat transfer capability of cooling system (Fig.6b). Hence, the active fan heat sink is more effective than simple large dimension heat sink and requires more mechanical reliability.

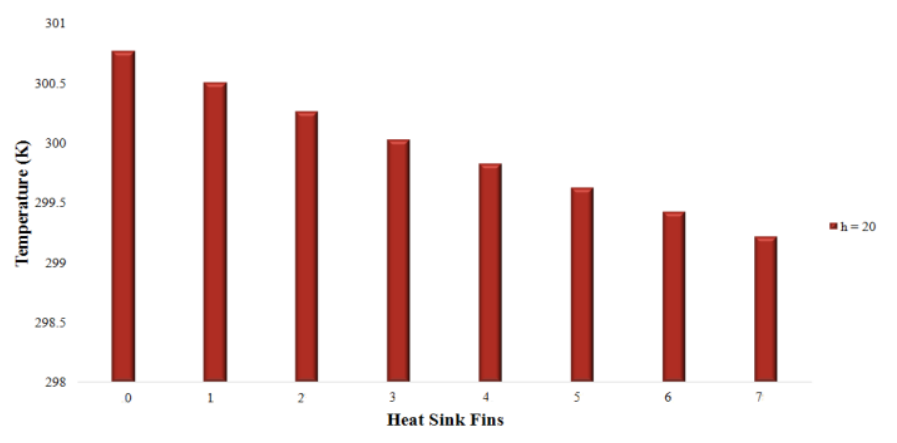

(a) Passive cooling

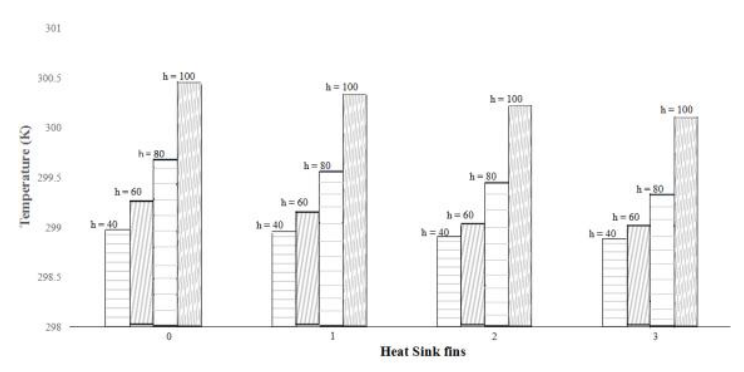

(b) Active cooling

Fig.6. (a) and (b) temperature variation over large dimension heat sink fins and active fan heat sink fins. $\mathrm{h}$ - Convection coefficient in $\mathrm{W} \times \mathrm{m}^{-2} \times \mathrm{K}^{-1}$ 


\section{Conclusion}

The paper describes the approach, which enables to present the dynamic thermal behaviour of parallel plate fine heat sink with U-shape channels. The proposed approach is based on the analogy between electrical and thermal parameters. Due to that, the transient thermal behaviour of the system may be analysed by using electric simulator program [7]. It might be an engineering solution to perform an adequate thermal analysis and temperature computation of a system in order to assess the cooling system capability. In addition, two different cooling techniques have been compared in order to assess their efficiency. Based on the data obtained from investigation, an increase of forced convection coefficient may considerably improve the cooling efficiency [10].

Finally, the methodology presented in this paper enables modelling of the dynamic thermal behaviour of parallel plate fin heat sink with U-shape channels.

Acknowledgment: The authors would like to express sincere gratitude to the National Science Center for financial support, project grant FALCON 2014/13/B/ST7/01634.

\section{References}

[1] Dan C.: Radiative Heat transfer in Electronics, 2005.

[2] De Mey G. and Kos A.: Optimal temperature control of high frequency semiconductor structures cooled by Peltier heat pumps

[3] Frankiewicz M., Golda A., Kos A.: Investigation of Heat Transfer In Integrated Circuits, Metrology and Measurement Systems, vol.11, No.1, 2014, pp.111-120.

[4] Kos A. and De Mey G.: Thermal Modelling and optimization of power microcircuits, Electrochemical Publications LTD, ISBN 0901150 3603, England 1997.

[5] Kos A.: Accuracy of Temperature Computation in Hybrid Microelectronics Microelectronics International, vol.9, Iss: 1, 1992, pp.25-27.

[6] Mikula S. and Kos A.: Thermal Dynamics of Multicore Integrated systems, Components and Packaging Technologies, IEEE Transactions, Vol.33, No. 3, September 2010, pp.524-534.

[7] J.O'Loughlin J. and Loree D.: Cooling System Transient Analysis using an Electric Circuit Program Analog, Pulsed Power Conference, 2003. Digest of Technical Papers. PPC-2003. 14th IEEE International (Volume: 2), June 2003, pp 767 - 770.

[8] Rencz M., Székely V., and Poppe A.: A Methodology for the Co-Simulation of Dynamic Compact Models of Packages With the Detailed Models of Boards, IEEE transactions on components and packaging technologies, vol.30, No.30, September 2007, pp.367 - 374 .

[9] Székely V. and Rencz M.: Thermal Dynamics and the time constant domain, IEEE transactions on components and packaging technologies, vol. 23, No.3, September 2000 , pp.587 - 594 . 
[10] Székely V., Rencz M., P'ahi A. and Courtois B.: Thermal Monitoring and Testing of Electronic systems, IEEE Transactions on components and packaging technology, vol.22, No.2, June 1999, pp.231-237.

[11] Tockhorn A., Cornelius C., Saemrow H. and Timmermann D.: Modeling Temperature Distribution in Networks-on-Chip using RC-Circuits, Design and Diagnostics of Electronic Circuits and Systems (DDECS), 2010 IEEE 13th International Symposium on, April 2010, pp. 229 - 232.

\section{PORÓWNANIE RÓŻNYCH SYSTEMÓW CHLODZENIA Z WYKORZYSTANIEM MODELU KOMPAKTOWEGO}

\section{Streszczenie}

Silny wpływ temperatury na własności układów scalonych wymaga analizy termicznej podczas projektowania konstrukcji modułu scalonego aby zapobiec uszkodzeniom tych układów. W artykule autorzy proponują podejście oparte na kompaktowym modelu RC, które prowadzi do oceny własności dynamicznych oraz wystarczająco dokładnej analizy termicznej w każdym punkcie pomiarowym radiatora $\mathrm{z}$ równoległymi płytkami chłodzącymi.

Słowa kluczowe: termiczny model kompaktowy, układ scalony, radiator, temperatura, aktywne chłodzenie

DOI: $10.7862 /$ re.2015.37

Tekst złożono $w$ redakcji: październik 2015

Przyjęto do druku: grudzień 2015 